\title{
IL-8 promotes proliferation and inhibition of apoptosis via STAT3/AKT/NF-кB pathway in prostate cancer
}

\author{
YIDI GUO $^{1 *}$, YING ZANG ${ }^{1 *}$, LIANZHENG LV ${ }^{1}$, FENG CAI $^{1}$, \\ TINGTING QIAN $^{1}$, GUOYING ZHANG ${ }^{1}$ and QUANCHENG FENG ${ }^{2}$, \\ ${ }^{1}$ Department of Clinical Laboratory, Nanjing Integrated Traditional Chinese and Western Medicine \\ Hospital Affiliated with Nanjing University of Chinese Medicine; ${ }^{2}$ Department of Nephrology, \\ Children's Hospital of Nanjing Medical University, Nanjing 210000, P.R. China
}

Received April 5, 2017; Accepted September 12, 2017

DOI: $10.3892 / \mathrm{mmr} .2017 .7747$

\begin{abstract}
Interleukin-8 (IL-8) possesses tumorigenic and proangiogenic properties, and is overexpressed in many human cancer types. However, only few studies have demonstrated the mechanisms of action of IL-8 regarding the ability to promote proliferation and to inhibit apoptosis in prostate cancer. Here, the aim of the present study was to investigate the effects of IL-8 on the prostate cancer cell line and determine possible mechanisms underlying its effect. In this study, IL-8 was shown to be significantly upregulated in prostate cancer compared with paired normal control tissues. The data showed that IL-8 exhibits direct oncogenicity, which significantly induced cell proliferation, invasion and attenuated apoptosis in prostate cancer cells via signal transducer and activator of transcription 3/protein kinase $\mathrm{B} /$ nuclear factor- $\mathrm{\kappa} \mathrm{B}$ signaling pathways. In conclusion, modulation of IL-8 expression or its associated signaling pathway may provide a novel working mechanism of IL-8 in prostate cancer, and a promising strategy for controlling the progression and metastasis of prostate cancer.
\end{abstract}

\section{Introduction}

Prostate cancer is one of the most common malignancies in men, and acts as one of leading cause of cancer-related death in the world, especially in some developed countries, although some therapy approaches have been used for prostate cancer therapy $(1,2)$. Most prostate cancer patients have metastases at the time of diagnosis leading to decreased treatment outcomes and poor survival rates (3). Despite the advances in treatment approaches over the past few decades, the treatment

Correspondence to: Dr Quancheng Feng, Department of Nephrology, Children's Hospital of Nanjing Medical University, 72 Street of Gangzhou, Nanjing 210000, P.R. China

E-mail: fqc_2017@sina.com

*Contributed equally

Key words: Interleukin-8, proliferation, apoptosis, signaling pathway outcome has not significantly improved $(4,5)$, proliferation and apoptosis is responsible for the main reason of death, and many patients with prostate cancer can progress to metastatic disease finally (6). Thus uncovering the molecular mechanism of prostate cancer cell proliferation and apoptosis is urgent and important. Therefore, the regulatory mechanism of prostate cancer progression must be further studied and gain a better understanding to identify novel therapeutic targets.

Interleukin-8 (IL-8), also known as CXCL-8, a member of the Glu-Leu-Arg (ELR) motifpositiveCysteine-X-Cysteine (CXC) chemokine family that is secreted by multiple cell types, including monocytes, neutrophils, endothelial and mesothelial cells, and tumor cells $(7,8)$. It was originally classified as a potent neutrophil chemoattractant, has been shown to regulate biological processes through interactions with relative receptors (9). Studies have shown that tumor progression and metastasis may be associated with overexpression of IL-8 $(10,11)$. In terms of tumor, IL-8 is known to participate in cancer progression by promoting the angiogenic response of endothelial cells, the recruitment of neutrophils to the site of the tumor, and the proliferation, survival and migration of tumor cells (12). Numerous studies have suggested that IL-8 plays a critical role during tumor angiogenesis, growth and metastasis in hepatocellular and nasopharyngeal carcinoma, gastric, lungcancer, prostate cancer (13-17), gastric and pancreatic carcinoma $(18,19)$. Induction of IL-8 expression is mediated primarily by activator protein and/or nuclear factor kappa B (NF-kB) (12).

STAT3/AKT/NF- $\mathrm{KB}$ play pivotal roles in various aspects of the tumorigenic process in several cancer entities, including colon, lung cancer, and hepatocellular carcinoma (20-22). These are powerful activators of malignancy and are pre-requisites for the expression of a variety of target genes that are important for cell proliferation, survival, angiogenesis, invasion, and metastasis (23). On the contrary, in immune cells, NF- $\kappa$ B and STAT3 control the expression of other cytokines and inflammatory/immune mediators that mediate NF- $\kappa B$ and STAT3 activation in cancer cells, including IL-1, IL-6, and TNF $\alpha$ (24). NF-кB physically interacts with STAT3, which may result in either specific transcriptional synergy or repression of NF- $\mathrm{\kappa B} / \mathrm{STAT} 3$ regulated genes (25). STAT3 may interact with RelA/p65 in the nucleus and prolong the presence of active NF- $\mathrm{KB}$ in the nucleus (25). Despite these versatile 
interactions, $\mathrm{NF}-\kappa \mathrm{B}$ and STAT3 cooperate to promote the development and progression of tumors (26).

However, the mechanisms of action of IL-8 in prostate cancer are largely unknown. The goal of the present study was explored the effect of IL-8 on tumor progression in prostate cancer, whether overexpression of endogenous IL- 8 in prostate cancer cells affects the malignant behavior, including in vitro anchorage-independent growth, proliferation, migration, invasion and apoptosis.

In addition, we explored the mechanisms by IL-8 overexpression to promotes proliferation and inhibition of apoptosis via STAT3/AKT/NF- $\mathrm{B}$ pathway in prostate cancer. These findings shed new light on prostate cancer pathogenesis and are helpful for developing innovative therapeutic strategy for prostate cancer patients.

\section{Materials and methods}

Tissue samples. Thirty patients with biopsyproven diagnosis of prostate cancer were enrolled in this study, tissues were collected from Gynecology Department, Children's Hospital of Nanjing Medical University. The corresponding adjacent non-neoplastic tissues from the macroscopic tumor margin were isolated at the same time and used as controls. All patients did not process chemotherapy or radiotherapy prior to surgery. These tissues were frozen in liquid nitrogen immediately after surgical removal and stored at $80^{\circ} \mathrm{C}$ until use. The study protocol was approved by the ethics committee of the Children's Hospital of Nanjing Medical University. The use of the tissue samples for all experiments were obtained with informed consent.

Cell culture. The human prostate cancer LNCap, PC-3, and DU-145 cells and normal prostate RPWE-1 cells were obtained from American Type Culture Collection (ATCC, Manassas, VA). These cells were cultured in RPMI-1640 media supplemented with $10 \%$ fetal bovine serum (FBS) and incubated in a humidified atmosphere containing $5 \% \mathrm{CO}_{2}$ at $37^{\circ} \mathrm{C}$.

Treatment with IL-8 of pancreatic cancer cell lines. $70 \%$ confluent prostate cancer cells were treated for $3 \mathrm{~d}$ with escalating concentrations of IL-8 $(10,30$ and $50 \mu \mathrm{g} / \mathrm{l})$ or medium alone. IL- 8 concentrations and the duration of cytokine treatment were based on our pilot experiments and our previous cytokine studies.

ELISA assay. Cells were growth in medium for 6 days, supernatants of prostate cancer cell lines were collected and frozen at $-20^{\circ} \mathrm{C}$ until the assay was performed. Cells were seeded into six-well plates and were starved overnight, then the cells were treated with the indicated concentrations of embelin in DMEM medium for $48 \mathrm{~h}$, the cell culture supernatant was collected, and the concentration of IL-8 was assessed using Legend Max human heterodimer IL-8 ELISA kit (Biolegend) according to the manufacturer's protocol. The $\mathrm{OD}_{405}$ was measured on a SpectraMax 340 counter using Soft-MAX PRO 1.2.0 software (Molecular Devices). All assays were performed in triplicate.

Western blot analysis. Total protein was collected and the protein concentration was measured by BCA protein assay kit
(Applygen Technologies Inc., Beijing, China). Equal amount of protein was added into SDS-PAGE gel, and then transferred to the polyvinylidene difluoride (PVDF) membrane. The membraneswere further blocked in TBST containing 5\% BSA for $1 \mathrm{~h}$, and then were incubated with primary antibody against IL- 8 and GAPDH at $4{ }^{\circ} \mathrm{C}$ overnight. The membranes were further washed for three times and were incubated with secondary antibodies for $1 \mathrm{~h}$. The bands were scanned and analyzed with with chemiluminescence with SuperSignal West Femto Chemiluminescent Substrate (Thermo Scientific, USA), and images were captured with a Bio-Rad camera system (Bio-Rad, USA). GAPDH were used as internal loading control.

Cell proliferation assay. Cells growth in vitro was detected by analyzing proliferative expansion of human prostate cancer cells (PC-3 and DU-145) with MTT assay and clonogenic survival assay. Briefly, prostate cancer cells were seeded at $5 \times 10^{3}$ cells each well and incubated with or without recombinant human IL-8 protein in 96-well plates and measured with MTT cell proliferation kit (Cayman Chemical) according to the manual's instructions. For clonogenic survival assay, cells were treated with IL- 8 after three days, the cells were detached and counted in a hemocytometer. Clonogenic survival assay was performed as described previously $(27,28)$. The number of colonies was counted and expressed as a percentage of total colonies in controls.

BrdU assay. Cell proliferation assay was measured by BrdU incorporation. Cell cultures grown on $13 \mathrm{~mm}$ round coverslips were incubated with a final concentration of $15 \mu \mathrm{l} \mathrm{BrdU}$ for $8 \mathrm{~h}$, after which time the cells were fixed with $4 \%$ paraformaldehyde for $10 \mathrm{~min}$ at room temperature. Coverslips were washed with PBS and then incubated for 10 min with $0.1 \%$ Triton-X100 to permeablize the membranes. The BrdU epitope was exposed by incubating the cells in $2 \mathrm{~N}$ hydrochloric acid for $1 \mathrm{~h}$ at $37^{\circ} \mathrm{C}$. Then endogenous peroxidase activity was quenched with $0.3 \%$ hydrogen peroxide in PBS for $30 \mathrm{~min}$ at room temperature. After being washed with PBS, cultures were blocked with $1 \%$ Bovine serum albumin and $2 \%$ normal goat serum in PBS (blocking solution). A primary antibody was added at a 1:200 dilution in blocking solution, and incubated at room temperature for $1 \mathrm{~h}$. Cells were washed three times with PBS and then incubated with secondary antibody at a 1:200 dilution for $1 \mathrm{hr}$ at room temperature in a blocking solution. BrdU was then detected with Tyramide-488 signal amplification (Invitrogen).

Cell migration and invasion assays. Cell migration assays were performed with wound healing assay. Briefly, cells were seeded into six-well plates and were starved overnight when the cells reached at least $95 \%$ confluence. A linear scratch was made using a $10 \mu \mathrm{l}$ micropipette tip. The cells were further cultured in DMEM medium containing 2\% fetal bovine serum. The width of the wound was photographed by light microscopy at 0, 24 and $48 \mathrm{~h}$. Each experiment was performed in triplicate. The measurements were obtained by measuring the distance of the wound using ImageJ software.

Furthermore, cell migration and invasion assays were performed using transwell plates (Millipore). For migration 
assay, $1.0 \times 10^{5}$ cells in $200 \mu \mathrm{l}$ of serum-free medium were placed in the upper chamber, whereas RPMI-1640 containing $20 \%$ BSA was placed in the lower chamber. The plates were incubated for $16 \mathrm{~h}$ at $37^{\circ} \mathrm{C}$ in $5 \% \mathrm{CO}_{2}$. For invasion assay, the upper chamber was coated with $30 \mu \mathrm{l}$ matrigel before used. Then $1.8 \times 10^{5}$ cells in $200 \mu 1$ of serum-free medium were placed in the upper chamber, whereas RPMI-1640 containing $20 \%$ BSA was placed in the lower chamber. Non-invading or non-migrating cells were removed from the upper surface by a cotton swab. The membrane was fixed with $4 \%$ formaldehyde and was stained with $0.5 \%$ crystal violet. Cells were counted in 5 different fields at $\times 200$ magnification, and the mean number of cells per field was calculated.

Cellular apoptosis assay. Apoptosis was determined by TUNEL (terminal deoxynucleotidyl transferase-mediated dUTP nick-end labeling) assa. Cells were treated with the indicated concentrations of embelin in complete medium for 48 h. Apoptosis was assessedusing an Apoptag kit (Chemicon) as previously described (27). To quantify the number of apoptotic cells, all cells in 5-6 randomly selected high power fields (magnification: 400) were manually counted using image analysis software MetaMorph. TUNEL and cells were expressed as a percentage of total cells.

Statistical analysis. All data were analyzed with SPSS 17.0 (SPSS Inc., Chicago, IL, USA), The results were represented as means \pm standard deviation (SD) at least three independent experiments. The statistical analysis was performed using a two-tailed unpaired t-test (between two groups) or a one-way analysis of variance (ANOVA) (among three or more groups), using the computer software SAS 9.2 (SAS Institute Inc., Cary, NC, USA). $\mathrm{P}<0.05$ was considered significant and $<0.01$ was considered statistically significant.

\section{Results}

Expression of IL-8 in prostate cancer tissues and cell lines. To detect the activity of IL- 8 in prostate cancer progression, firstly, we localized IL-8 expression in tumor tissues and adjacent tissues from prostate cancer patients. IL-8 was commonly shown to be pronouncedly up-regulated in tumor tissues compared with paired normal control (Fig. 1A). Furthermore, we detected the level of IL-8 in the supernatant of RPWE-1, LNCap, PC-3, and DU-145 cells. The results showed that the level of IL-8 was elevated in prostate cancer cells as compared to that in RPWE-1 cells (Fig. 1B). On the whole, these data suggest that IL-8 may play a role in prostate cancer.

IL-8 promotes proliferation of prostate cancer cells. To observe the effect of IL-8 over proliferation of prostate cancer cells, MTT assay was conducted on PC-3 and DU-145 cell lines in respective after it were treated with escalating doses of IL-8 $(10,30$, or $50 \mu \mathrm{g} / 1)$ or medium alone for 3 days. It was shown that IL-8 was found to be markedly capable of promoting proliferation compared with control group in PC-3 and DU-145 cells (Fig. 2A and B). To further confirm the direct effect of IL-8 on prostate cancer cells proliferation, cell survival was evaluated by BrdU cell proliferation assay and clonogenic survival assay (Fig. 2C and D). The percentage of
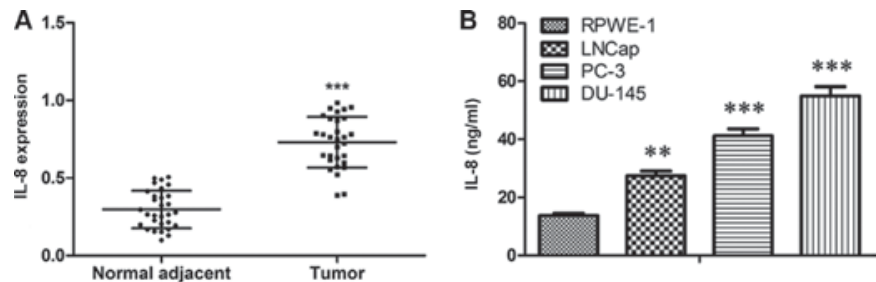

Figure 1. Expression of IL-8 in prostate cancer tissues and cell lines. (A) IL-8 expressions in tumor tissues and adjacent tissues from prostate cancer patients $(\mathrm{n}=30)$ were determined, ${ }^{* * *} \mathrm{P}<0.001$ vs. normal adjacent. (B) The level of IL-8 in supernatant of normal prostate RPWE-1 cells and prostate cancer LNCap, PC-3, and DU-145 cells, ${ }^{* *} \mathrm{P}<0.01$ and ${ }^{* * *} \mathrm{P}<0.001$ vs. RPWE-1.

colonies of PC-3 and DU-145 cells treated with IL-8 at the concentration of $10 \mu \mathrm{g} / \mathrm{l}$ was comparable with that in controls treated with medium alone, while the percentage of colonies of cells was higher at $30 \mu \mathrm{g} / 1$ of IL- 8 and the highest at the concentration of $50 \mu \mathrm{g} / \mathrm{l}$. Thus, our results indicate that IL-8 promotes survival and proliferation of prostate cancer cells.

IL-8 promotes migration and invasion of prostate cancer cells. Subsequently, to observe the effect over migration and invasion of prostate cancer cells by IL-8, wound-healing and transwell assays were carried out after treated with escalating concentrations of IL-8 $(10,30$ and $50 \mu \mathrm{g} / \mathrm{l})$ or medium alone. Firstly, we investigate the effects of IL- 8 on migration about prostate cancer cells by using scratch wound healing and in vitro transwell assays. As shown in Fig. $3 \mathrm{~A}$ and $\mathrm{B}$, the extent of wound healing was inversely proportional to the concentrations and duration of embelin treatment. It was displayed that IL-8 was found to be remarkably able to promote the migration (Fig. 3C and D) of PC-3 and DU-145 cells. We then examined the role of IL-8 in prostate cancer cell invasion by using transwell assays (Fig. 3E and F), The migrating and invading cells on the lower surface of the filter were stained and counted. The bar graphs show the number of migrating and invading cells for each category of the cells. Thus, IL-8 was shown to have capacity for abrogating the effect over migratory and invasive abilities in PC-3 and DU-145 cells, suggesting that IL-8 can migration and invasion of prostate cancer cells in vitro.

IL-8 decreases apoptosis of prostate cancer cells. In addition to enhanced proliferation, decrease of apoptosis could also result in IL-8 promotion of prostate cancer cells growth. To address this possible effect of IL-8, we examined apoptosis of PC-3 and DU-145 cells treated with IL-8. The cells were treated with IL-8 $(10,30$ and $50 \mu \mathrm{g} / \mathrm{l})$ or medium alone for 3 days and apoptosis was evaluated by TUNEL staining. As shown in Fig. 4A and B, cells were were treated with IL-8, the number of apoptotic cells is visibly decreased compared to the control group. Moreover, the number of apoptotic cells was inversely proportional to the concentration of IL-8. It was displayed that IL-8 was found to be remarkably able to inhibit the apoptosis. Since the DU-145 cells proliferation ability was faster than PC-3 cells, so the number of apoptotic cells in DU-145 cells was more than of PC-3 cells under the same conditions. The apoptosis-related proteins expression was detected by western blot. Similar results were obtained, Bax, Caspase-3 and Caspase-9 expression was obviously decreased 
A

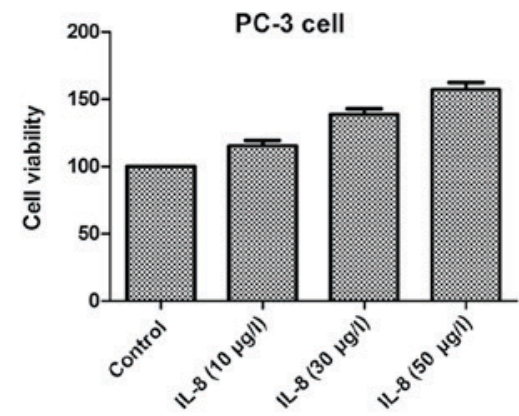

B

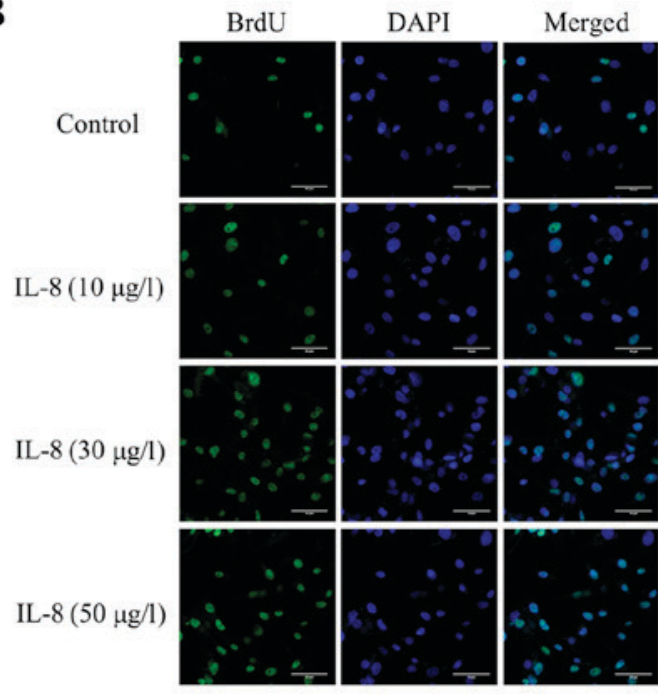

\section{C}
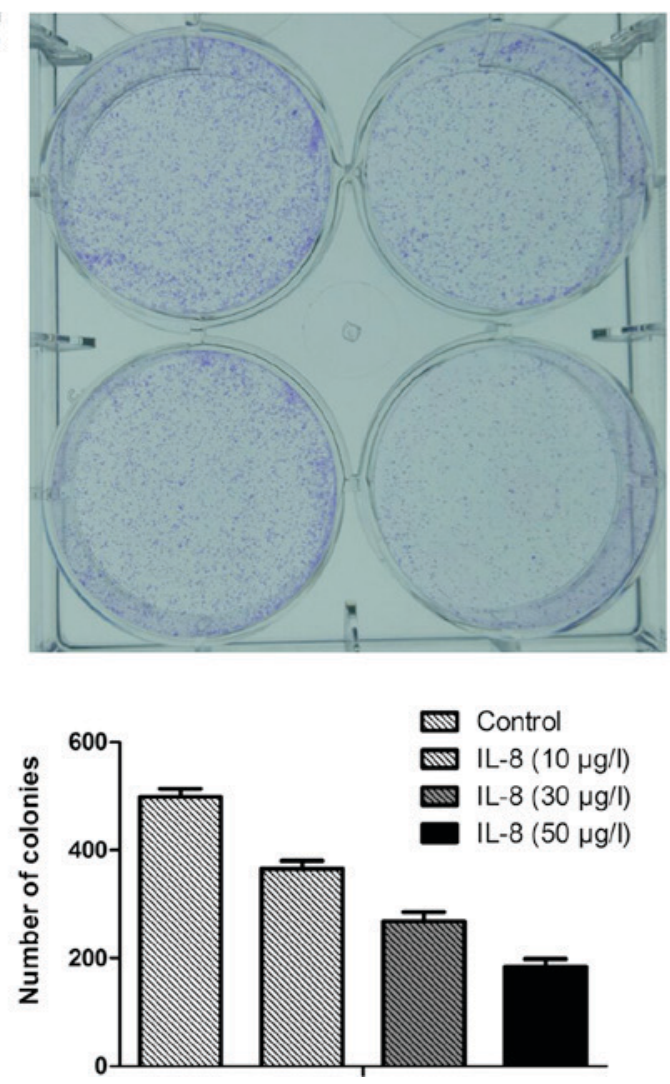
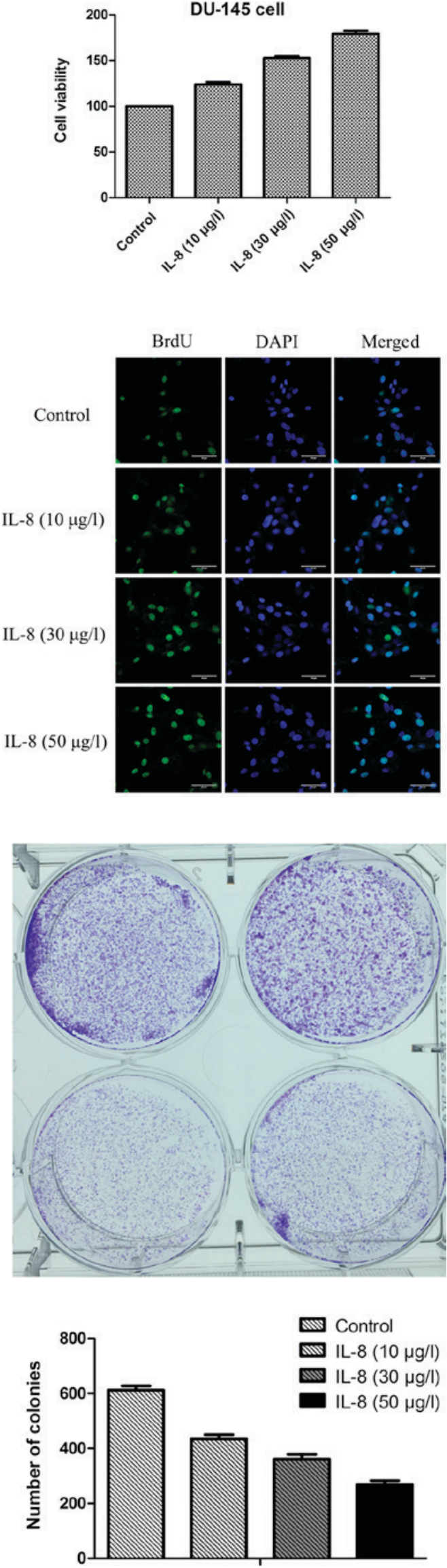

Figure 2. IL-8 promotes proliferation of prostate cancer cell lines. (A) IL-8 was observed to be markedly able to promote proliferation in PC-3 cells. Up-expression of IL-8 was found to be capable of promoting proliferation of prostate cancer cell line DU-145. (B) BrdU Cell Proliferation Assay to demonstrate the cell proliferation. (C) the clonogenic survival assay of PC-3 cells with variable dosage of IL- 8 . The number of colonies was counted and expressed as a percentage of total colonies in controls. Similar observation was also made in DU-145 cells as did in PC-3 cells. Results are expressed as the mean \pm SEM in each group, and are representative of three independent experiments. 


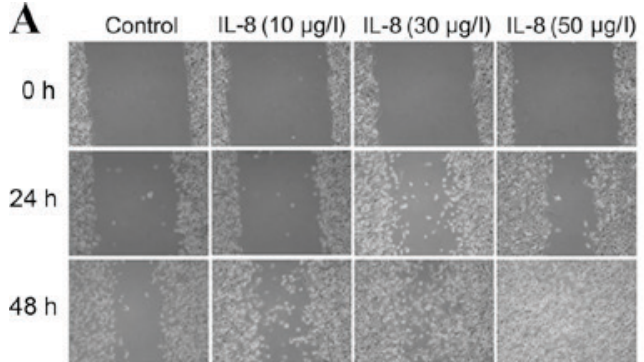

PC-3

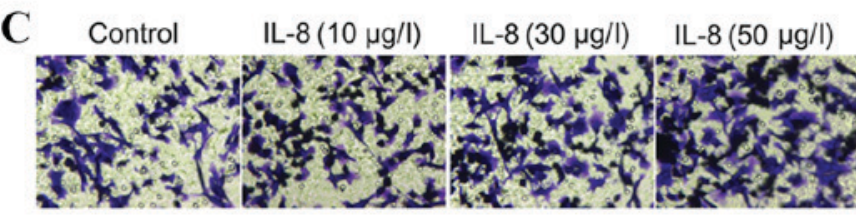

$\mathrm{PC}-3$

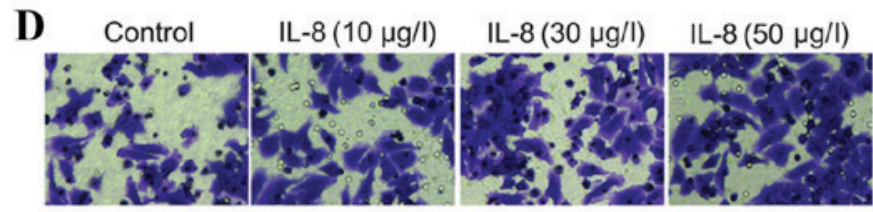

DU-145

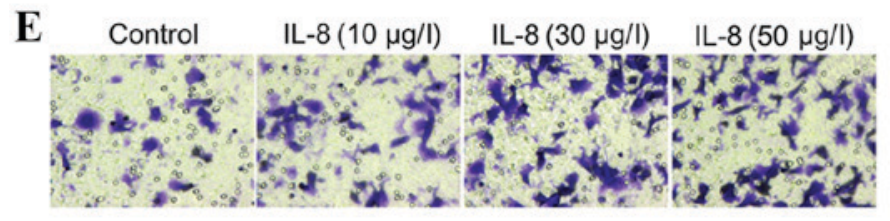

PC-3

$\mathbf{F}$

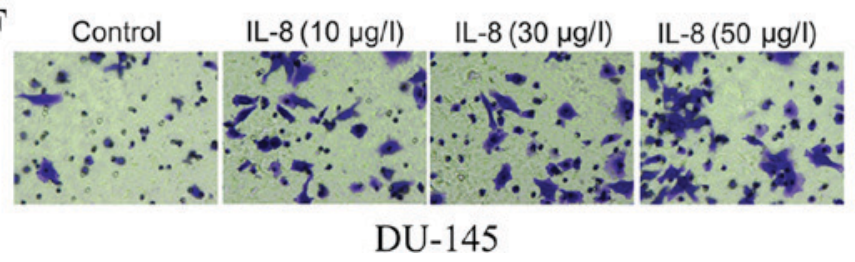

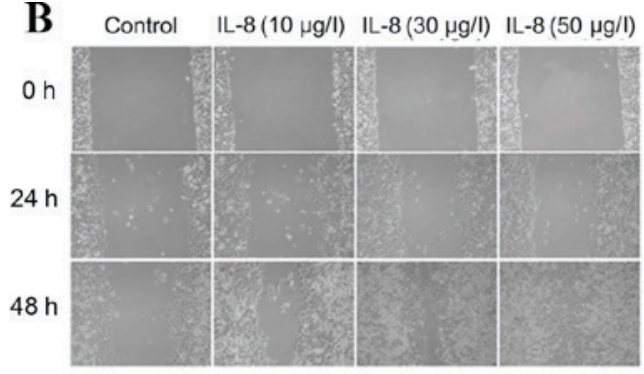

DU-145
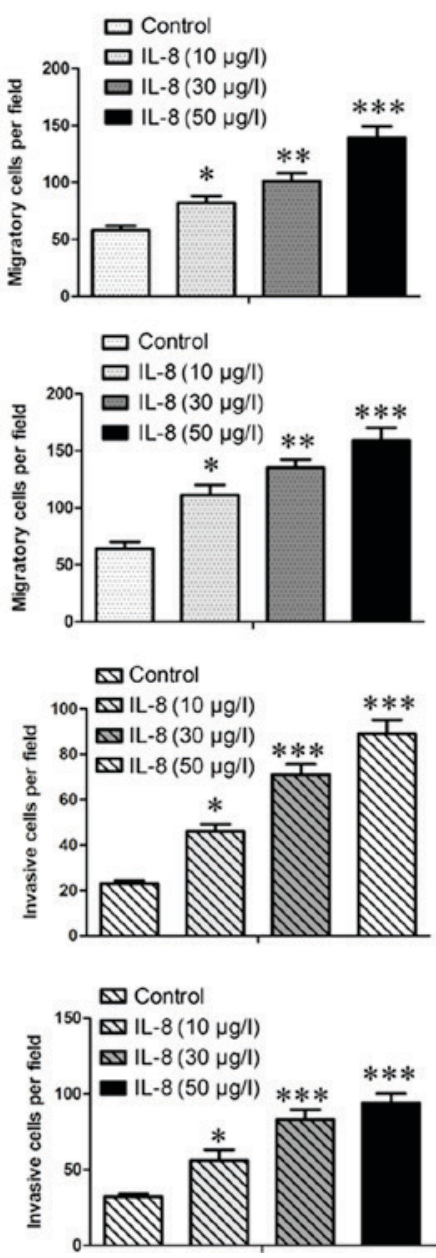

Figure 3. Effect of IL-8 on prostate cancer cell migration and invasion. (A and B) Scratch wound healing assay was used to assess cell motility in PC-3 cells. The wound closure was viewed under bright field and photographed with an inverted lightmicroscope. (C-F) Transwell migration (top panel) and invasion (bottom panel) assays were used to assess cellular motility and invasion ability. Similar observation was made in DU-145 cells as did in PC-3. Data are expressed as the mean $\pm \mathrm{SD}$. Experiments were performed at least twice, and similar results were obtained, ${ }^{*} \mathrm{P}<0.05,{ }^{* * *} \mathrm{P}<0.01$ and ${ }^{* * * *} \mathrm{P}<0.001 \mathrm{vs}$. control.

in cells were were treated with IL-8 at the protein level compared to the control group. On the contrary, Bcl-2 expression was obviously increased (Fig. 4C and D). These results suggest that IL-8 inhibits apoptosis of prostate cancer cells.

IL-8 induces activation of STAT3/AKT/NF- $\kappa B$ pathway in prostate cancer cells. STAT3/AKT/NF- $\kappa \mathrm{B}$ pathway plays an important role in cancer progression. Here, after stimulating with different concentration of IL- 8 for $1 \mathrm{~h}$, we found that IL-8 dose-dependently induced activation of STAT3/AKT/NF-кB in prostate cancer cells. Here, we investigated whether the STAT3 and Akt pathways participate in the promoting proliferation capacity of IL-8 in PC-3 and DU-145 cells. As shown in Fig. 5A, B, The phosphorylation of STAT3 was evaluated by the proportion of $\mathrm{p}-\mathrm{STAT} 3$ and STAT3. The ratio of p-STAT3 and STAT3 in cells was significantly larger than the one in cells with control in PC-3 cells. We next examined whether IL-8 could induce the AKT pathway in prostate cancer cells. Western blot analysis showed that IL-8 time-dependently induced activation of AKT in prostate cancer cells. The cells which treat with IL-8 significantly increased the phosphorylated level of AKT protein compared to the control. Gray analysis showed that the ratio of p-AKT and AKT in cells treat with IL-8 was significantly higher than the one in cells with control. We further detected the effect of IL-8 on activation of $\mathrm{NF}-\kappa \mathrm{B}$ in prostate cancer cells. Using western blotting, we 


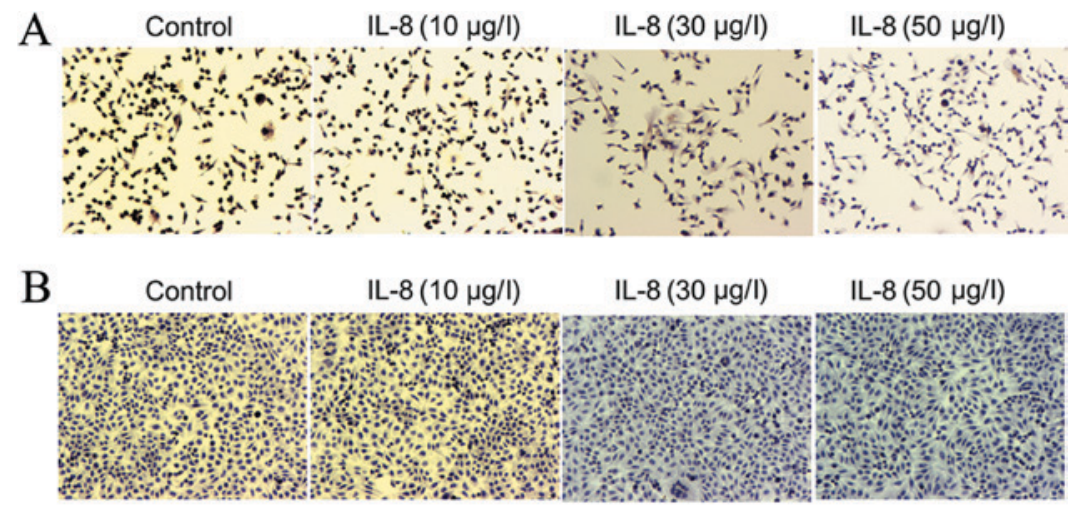

$\mathrm{C}$

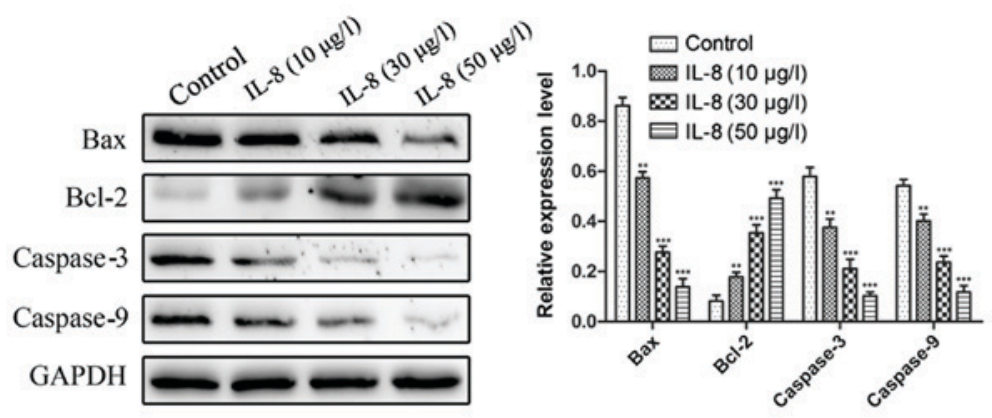

$\mathrm{D}$

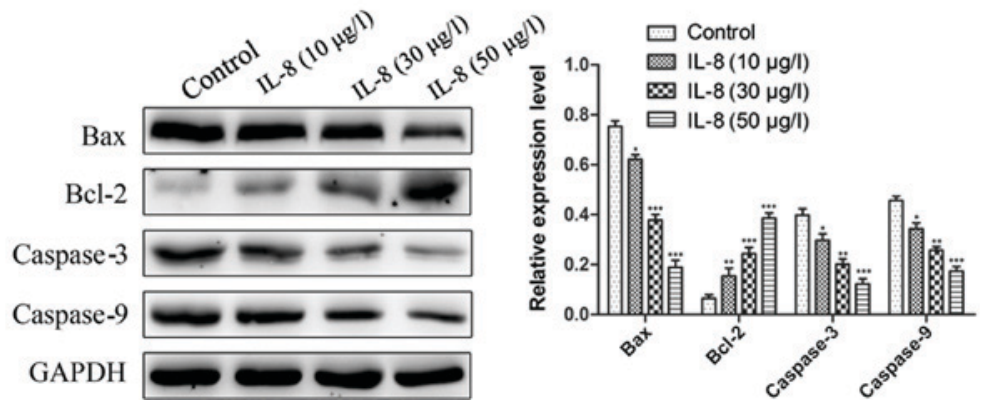

Figure 4. IL-8 decreases apoptosis of prostate cancer cells. (A) representative TUNEL staining is shown on PC-3 cells. (B) DU-145 cells apoptosis is shown by TUNEL staining (C and D) Cellular caspase-3 Caspase-9 Bax and Bcl-2 activity was measured as described in methods about PC-3 and DU-145 cells. lane $1=$ control; lane 2=IL-8 $(10 \mu \mathrm{g} / \mathrm{l})$; lane $3=\mathrm{IL}-8(30 \mu \mathrm{g} / \mathrm{l})$; lane 4=IL-8 $(50 \mu \mathrm{g} / \mathrm{l})$. Results are expressed as mean activity relative to controls \pm SEM. Assays were done in triplicate. ${ }^{*} \mathrm{P}<0.05,{ }^{* * *} \mathrm{P}<0.01$ and ${ }^{* * * *} \mathrm{P}<0.001$ vs. control.

found that IL-8 stimulation time-dependently induced phosphorylation of NF- $\mathrm{kB}$ P65. The similiar results was obstained in DU-145 cells (Fig. 5C, D). For in all, our results demonstrate that IL-8 could induce activation of STAT3/AKT/NF- $\mathrm{BB}$ in prostate cancer cells.

\section{Discussion}

In current study, we determine a close correlation of IL-8 expression with prostate cancer progression in clinical patients. IL-8 was shown to be significantly up-regulated in prostate cancer tissues in comparison with paired normal control tissues. Over-expression of IL- 8 can be a common phenomenon that was readily seen in different types of cancer, including oral squamous cell carcinoma, multiple myeloma, hepatocarcinoma, chronic lymphocytic leukemia (29-33) melanoma, colon carcinoma, and pancreatic cell lines $(29,34)$. Many studies have addressed the role of IL-8 in promoting cell proliferation, migration, and invasion of cancer cells $(17,35)$, and more recently, has received attention in assisting cancer cells to evade stress-induced apoptosis (36). Consistent with the preponderance of effects indicated from in vitro studies, the expression of IL-8 has been shown to correlate with the angiogenesis, tumorigenicity, and metastatic potential of many solid cancers in xenograft and orthotopic in vivo models (37).

However, the role of IL-8 about the detailed mechanisms underlying cell proliferation and apoptosis in prostate cancer is not been reported at present. In this study, we found that abilities of cell proliferation was enhanced and cell apoptosis was inhibited in IL-8 overexpressed cells compared with their respective control cells, indicating that IL-8 might increase proliferation and inhibite apoptosis of prostate cancer cells. Firstly, we find that IL-8 expression promotes growth of prostate cancer, as evidenced by MTT assay and soft agar colony formation assay. In addition, we also find that IL-8 expression inhibit apoptosis of prostate cancer cells, as evidenced by TUNEL staining and western blot. These findings provide direct evidence that the IL-8 promotes cell proliferation and inhibit apoptosis in prostate cancer.

According to previous published results for IL-6 and IL-8, we found that IL-8 up-regulation in stromal cells because of 

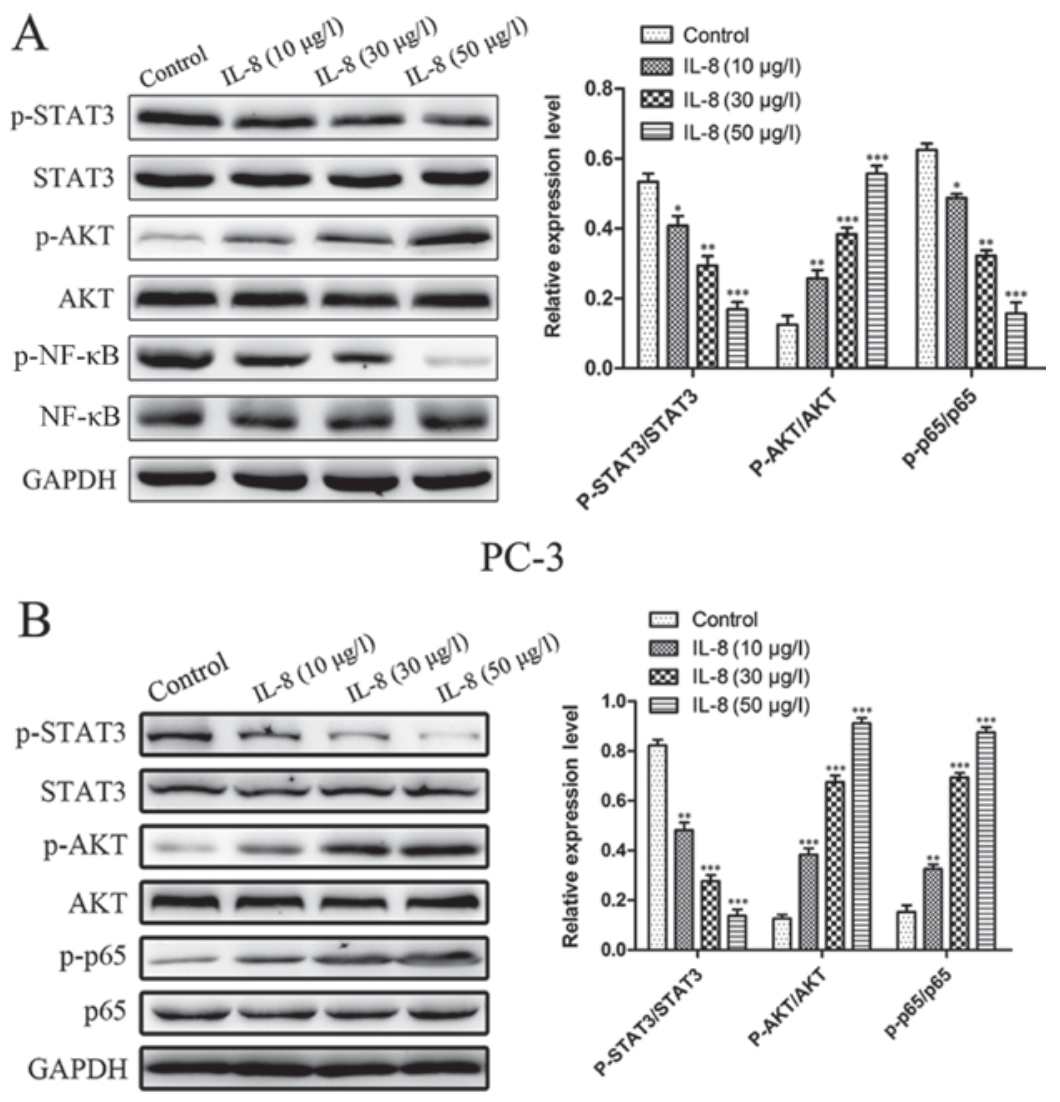

DU-145

Figure 5. Effect of IL-8 on activation of STAT3/AKT/NF- $\mathrm{BB}$ in prostate cancer cells. (A) Prostate cancer cells were stimulated with IL-8 respectively. PC-3 cells were incubated with IL-8 for $3 \mathrm{~d}$ respectively, STAT3/AKT/NF-kB activation was detected by western blotting. Three independent tests were carried out and each group was made in triplicate. (B) Gray analysis showed that the ratio of proteins in PC-3 cells was significantly higher than the one with control, $\mathrm{P}<0.01$. Similar observation was made in DU-145 cells as did in PC-3. lane 1=control; lane 2=IL-8 (10 $\mu \mathrm{g} / \mathrm{l})$; lane $3=\mathrm{IL}-8(30 \mu \mathrm{g} / \mathrm{l}) ; \mathrm{lane} 4=\mathrm{IL}-8(50 \mu \mathrm{g} / \mathrm{l})$. ${ }^{*} \mathrm{P}<0.05,{ }^{* * *} \mathrm{P}<0.01$ and ${ }^{* * * *} \mathrm{P}<0.001$ vs. control.

interaction with IM9 cells was partially mediated by the transcription factor NF- $\mathrm{NB}$ (38) and other mechanisms including AP-1, NF- $\kappa$ B, STAT-3 and $\beta$-catenin signaling pathways could also be involved in IL-8-induced tumor migration (12). Research previously demonstrated that IL-27 could inhibit tumor growth directly dependent of the STAT1 signalpathway in mouse melanoma. Moreover, STAT3 and STAT5 signal pathways also participated in the antitumor activity of IL-27. However, there have been few studies reporting the correlation between IL- 8 and the STAT3, AKT signal pathway as well as $\mathrm{NF}-\kappa \mathrm{B}$ expression in tumor studies. To investigate the underlying mechanism, we've explored the role of IL-8 in vitro in prostate cancer cells. Our study showed that IL-8 could promote prostate cancer cells proliferation and inhibit apoptosis by activate the STAT3, AKT and NF- $\kappa$ B expression. $\mathrm{NF}-\kappa \mathrm{B}$ is a transcription factor that plays an important role in carcinogenesis as well as in the regulation of immune and inflammatory response. Aberrant or constitutive NF- $\mathrm{NB}$ activation has been linked to cell transformation, proliferation, survival, invasion, angiogenesis, and metastasis (12).

The AKT pathway is a major cascade that promotes the activation of the NF- $\mathrm{KB}$ signaling pathway in human cancer cells (40). In various cells, phospho-AKT and NF- $\kappa \mathrm{B}$ work as antiapoptotic factors by phosphorylating bad to prevent its binding to $\mathrm{Bcl}-2$. In unstimulated cells, $\mathrm{NF}-\kappa \mathrm{B}$ exists in the cytoplasm as an inactive form bound to an inhibitor protein called $\mathrm{I} \kappa \mathrm{B}$, which can be phosphorylated by I $\mathrm{B}$ kinase (41). The various stimuli activate $\mathrm{NF}-\kappa \mathrm{B}$, causing phosphorylation of $\mathrm{I} \kappa \mathrm{B}$. Then I $\mathrm{B} \alpha$ is phosphorylated and separates from the p50-p65-I $\kappa \mathrm{B} \alpha$ heterotrimer. Finally, phosphorylation and nuclear translocation of $\mathrm{p} 65$ to the nucleus leads to activation

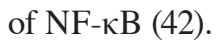

In this context, We here found that IL- 8 axis induced the activation of $\mathrm{NF}-\kappa \mathrm{B}$ via upregulation of phosphorylated AKT. Then we demonstrated that IL-8 activated the canonical $\mathrm{NF}-\kappa \mathrm{B}$ pathway, increased nuclear p65. Our work deeply clarified that IL-8 in vitro can prevent the release of cytochrome $\mathrm{c}$ from mitochondria and prevent cleavage of caspase 3 . This is another demonstration that IL- 8 treatment stabilizes the mitochondrial membrane and prevents of release of cytochrome c, effects that are likely to be because of the increased expression of Bcl-2.

In summary, our study demonstrated that IL-8 increased cell proliferation and inhibit apoptosis via the STAT3/AKT/NF- $\kappa$ B pathways in prostate cancer cell lines. It is crucial to prevent prostate cancer, the discovery of an IL-8-mediated signaling pathway helps to better understand the mechanism of prostate cancer metastasis and may contribute to the development of therapeutic strategies in the future. 


\section{Acknowledgements}

The present study was supported by the topic of Nanjing Municipal Health Bureau (no. YKK14162).

\section{References}

1. Siegel RL, Miller KD and Jemal A: Cancer statistics, 2016. CA Cancer J Clin 66: 7-30, 2016.

2. Watson PA, Arora VK and Sawyers CL: Emerging mechanisms of resistance to androgen receptor inhibitors in prostate cancer. Nat Rev Cancer 15: 701-711, 2015.

3. Coleman RE: Clinical features of metastatic bone disease and risk of skeletal morbidity. Clin Cancer Res 12: 6243s-6249s, 2006.

4. Edlind MP and Hsieh AC: PI3K-AKT-mTOR signaling in prostate cancer progression and androgen deprivation therapy resistance. Asian J Androl 16: 378-386, 2014.

5. González-Alonso P, Cristóbal I, Manso R, Madoz-Gúrpide J, García-Foncillas J and Rojo F: PP2A inhibition as a novel therapeutic target in castration-resistant prostate cancer. Tumor Biol 36: 5753-5755, 2015.

6. Bratt $\mathrm{O}$ and Schumacher MC: Natural history of prostate cancer, chemoprevention and active surveillance. Acta Oncol (50 Suppl 1): S116-S119, 2011.

7. Dai Y, Qiao L, Chan KW, Yang M, Ye J, Ma J, Zou B, Gu Q, Wang J, Pang R, et al: Peroxisome proliferator-activated receptor-gamma contributes to the inhibitory effects of Embelin on colon carcinogenesis. Cancer Res 69: 4776-4783, 2009.

8. Zmijewski MA and Slominski AT: Neuroendocrinology of the skin: An overview and selective analysis. Dermatoendocrinol 3: 3-10, 2011.

9. Kim SW, Kim SM, Bae H, Nam D, Lee JH, Lee SG, Shim BS Kim SH, Ahn KS, Choi SH, et al: Embelin inhibits growth and induces apoptosis through the suppression of Akt/mTOR/S6K1 signaling cascades. Prostate 73: 296-305, 2013.

10. Xie K: Interleukin-8 and human cancer biology. Cytokine Growth Factor Rev 12: 375-391, 2001.

11. Tanaka T, Bai Z, Srinoulprasert Y, Yang BG, Hayasaka H and Miyasaka M: Chemokines in tumor progression and metastasis. Cancer Sci 96: 317-322, 2005.

12. Waugh DJ and Wilson C: The interleukin-8 pathway in cancer. Clin Cancer Res 14: 6735-6741, 2008.

13. Yu J, Ren X, Chen Y, Liu P, Wei X, Li H, Ying G, Chen K, Winkler $\mathrm{H}$ and Hao $\mathrm{X}$ : Dysfunctional activation of neurotensin/IL-8 pathway in hepatocellular carcinoma is associated with increased inflammatory response in microenvironment, more epithelial mesenchymal transition in cancer and worse prognosis in patients. PLoS One 8: e56069, 2013.

14. Li XJ, Peng LX, Shao JY, Lu WH, Zhang JX, Chen S, Chen ZY, Xiang YQ, Bao YN,Zheng FJ, et al: As an independent unfavorable prognostic factor, IL-8 promotes metastasis of nasopharyngeal carcinoma through induction of epithelial-mesenchymal transition and activation of AKT signaling. Carcinogenesis 33: 1302-1309, 2012.

15. Kido S, Kitadai Y, Hattori N, Haruma K, Kido T, Ohta M, Tanaka S, Yoshihara M, Sumii K, Ohmoto Y and Chayama K: Interleukin 8 and vascular endothelial growth factor-prognostic factors in human gastric carcinomas? Eur J Cancer 37: 1482-1487, 2001.

16. Yuan A, Yang PC, Yu CJ, Chen WJ, Lin FY, Kuo SH and Luh KT: Interleukin-8 messenger ribonucleic acid expression correlates with tumor progression, tumor angiogenesis, patient survival, and timing of relapse in non-small-cell lung cancer. Am J Respir Crit Care Med 162: 1957-1963, 2000.

17. Araki S, Omori Y, Lyn D, Singh RK, Meinbach DM, Sandman Y, Lokeshwar VB and Lokeshwar BL: Interleukin-8 is a molecular determinant of androgen independence and progression in prostate cancer. Cancer Res 67: 6854-6862, 2007.

18. Kuai WX, Wang Q, Yang XZ, Zhao Y, Yu R and Tang XJ: Interleukin- 8 associates with adhesion, migration, invasion and chemosensitivity of human gastric cancer cells. World J Gastroenterol 18: 979-985, 2012.

19. Li M, Zhang Y, Feurino LW, Wang H, Fisher WE, Brunicardi FC Chen $\mathrm{C}$ and Yao Q: Interleukin-8 increases vascular endothelia growth factor and neuropilin expression and stimulates ERK activation in human pancreatic cancer. Cancer Sci 99: 733-737, 2008.
20. Shalapour $S$ and Karin M: Immunity, inflammation, and cancer: An eternal fight between good and evil. J Clin Invest 125: 3347-3355, 2015.

21. Didonato JA, Mercurio F and Karin M: NF- $\kappa \mathrm{B}$ and the link between inflammation and cancer. Immunol Rev 246: 379-400, 2012.

22. He G and Karin M: NF- $\mathrm{BB}$ and STAT3-key players in liver inflammation and cancer. Cell Res 21: 159-168, 2011.

23. Fan Y, Mao R and Yang J: NF- $\kappa$ B and STAT3 signaling pathways collaboratively link inflammation to cancer. Protein Cell 4: 176-185, 2013.

24. Grivennikov SI and Karin M: Inflammation and oncogenesis: A vicious connection. Curr Opin Genet Dev 20: 65-71, 2010.

25. Grivennikov SI and Karin M: Dangerous liaisons: STAT3 and NF-kappaB collaboration and crosstalk in cancer. Cytokine Growth Factor Rev 21: 11-19, 2009.

26. Terlizzi M, Casolaro V,Pinto A and Sorrentino R: Inflammasome: Cancer's friend or foe? Pharmacol Ther 143: 24-33, 2014.

27. Fang Y, Demarco VG and Nicholl MB: Resveratrol enhances radiation sensitivity in prostate cancer by inhibiting cell proliferation and promoting cell senescence and apoptosis. Cancer Sci 103: 1090-1098, 2012.

28. Fang Y, Herrick EJ and Nicholl MB: A possible role for perforin and granzyme B in resveratrol-enhanced radiosensitivity of prostate cancer. J Androl 33: 752-760, 2011

29. Fujita Y, Okamoto M, Goda H, Tano T, Nakashiro K, Sugita A, Fujita T, Koido S, Homma S, Kawakami Y and Hamakawa H: Prognostic significance of interleukin-8 and CD163-positive cell-infiltration in tumor tissues in patients with oral squamous cell carcinoma. PLoS One 9: e110378, 2014.

30. Punyani SR and Sathawane RS: Salivary level of interleukin- 8 in oral precancer and oral squamous cell carcinoma. Clin Oral Investig 17: 517-524, 2013.

31. Herrero AB, Garcíagómez A, Garayoa M, Corchete LA, Hernández JM, San Miguel J and Gutierrez NC: Effects of IL-8 up-regulation on cell survival and osteoclastogenesis in multiple myeloma. Am J Pathol 186: 2171-2182, 2016.

32. Perbellini O, Cioffi F, Malpeli G, Zanolin E, Lovato O, Scarpa A Pizzolo G and Scupoli MT: Up-regulation of CXCL8/interleukin-8 production in response to CXCL12 in chronic lymphocytic leukemia. Leuk Lymphoma 56: 1897-1900, 2015.

33. Brew R, Erikson JS, West DC, Kinsella AR, Slavin J and Christmas SE: Interleukin- 8 as a growth factor for human colorectal carcinoma cells in vitro. Cy tokine 12: 78-85, 2000.

34. Singh S, Singh AP, Sharma B, Owen LB and Singh RK: CXCL8 and its cognate receptors in melanoma progression and metastasis. Future Oncol 6: 111-116, 2010.

35. Yao C, Lin Y, Chua MS, Ye CS, Bi J, Li W, Zhu YF and Wang SM: Interleukin-8 modulates growth and invasiveness of estrogen receptor-negative breast cancer cells. Int J Cancer 121: 1949-1957, 2007.

36. Singh RK and Lokeshwar BL: Depletion of intrinsic expression of Interleukin-8 in prostate cancer cells causes cell cycle arrest, spontaneous apoptosis and increases the efficacy of chemotherapeutic drugs. Mol Cancer 8: 57, 2009.

37. Karashima T, Sweeney P, Kamat A, Huang S, Kim SJ, Bar-Eli M, McConkey DJ and Dinney CP: Nuclear factor-kappaB mediates angiogenesis and metastasis of human bladder cancer through the regulation of interleukin-8. Clin Cancer Res 9: 2786-2797, 2003.

38. Kline M, Donovan K, Wellik L, Lust C, Jin W, Moon-Tasson L, Xiong Y, Witzig TE, Kumar S, Rajkumar SV and Lust JA: Cytokine and chemokine profiles in multiple myeloma; significance of stromal interaction and correlation of IL-8 production with disease progression. Leuk Res 31: 591-598, 2007.

39. Karin M: Nuclear factor-kappaB in cancer development and progression. Nature 441: 431-436, 2006

40. Shrimali D, Shanmugam MK, Kumar AP, Zhang J, Tan BK, Ahn KS and Sethi G: Targeted abrogation of diverse signal transduction cascades by emodin for the treatment of inflammatory disorders and cancer. Cancer Lett 341: 139-149, 2013.

41. Profita M, Bonanno A, Siena L, Ferraro M, Montalbano AM, Pompeo F, Riccobono L, Pieper MP and Gjomarkaj M: Acetylcholine mediates the release of IL-8 in human bronchial epithelial cells by a NFkB/ERK-dependent mechanism. Eur J Pharmacol 582: 145-153, 2008.

42. Nguyen DP, Li J, Yadav SS and Tewari AK: Recent insights into $\mathrm{NF}-\kappa \mathrm{B}$ signalling pathways and the link between inflammation and prostate cancer. BJU Int 114: 168-176, 2013. 